\title{
Recall of boxed material in textbooks
}

\author{
HOLLY R. MILLER and STEPHEN F. DAVIS \\ Emporia State University, Emporia, Kansas
}

\begin{abstract}
College students read sections of a textbook that included both regular and boxed material, and took a multiple-choice test over the material $24 \mathrm{~h}$ later. Subjects instructed to attend to boxed material scored significantly higher on questions covering this material than did subjects not so instructed.
\end{abstract}

The conventional textbook features regular text and material that stands apart from the regular text. This second type of material often appears in boxes enhanced by different colors. Such boxes contain graphs, examples, or new findings that warrant special attention, but highlighting material in this way does not guarantee that it will be read and remembered.

Although data pertaining to the recall of boxed material have not been reported, research concerning the recall of other special textual features has. For example, Goldstein, Bailis, and Chance (1983) reported that subjects attended to and remembered pictures in textbooks, but Kumar (1975) reported that $77 \%$ of the adjunct questions presented in six chapters of an educational psychology text "were either ignored or scanned" (p. 179). Both reports called for additional research to ascertain more effective use of these techniques. Goldstein et al. (1983) indicated that "if students remembered pictures which they learned 'incidentally' they should be able to profit even more from illustrations which are both integrated carefully into the text and are also called to the attention of the reader instead of simply "being there',' (p. 25).

Bolger (1990, April) presented preliminary data demonstrating a positive relation between the time students spent reading boxed material and their scores on a later test over that material. Because this same pattern of results also occurred for regular text, however, Bolger's data do not indicate whether there is differential comprehension of regular and boxed material. Moreover, Bolger used different types of questions to evaluate comprehension of these two types of material, thus precluding direct comparisons.

We directly evaluated students' comprehension of regular and boxed material. One group of subjects (specified condition) was specifically instructed to read both regularand boxed-text material. A second group of subjects (general condition) was instructed to read the designated section of text, but no specific reference was made to the boxed material. Differences in recall were evaluated by a multiple-choice test taken $24 \mathrm{~h}$ later.

\footnotetext{
We thank Macmillan Publishing Company for supplying the textbooks used in this experiment. Requests for reprints should be sent to either author, Department of Psychology, Emporia State University, Emporia, KS 66801 .
}

\section{METHOD}

\section{Subjects}

Fifty-eight college students ( 31 women, 27 men) in introductory psychology courses at Emporia State University voluntarily served as subjects. All subjects completed an informed consent form before participating.

\section{Textual Material and Testing Instrument}

The textual material for this study came from an introductory marketing textbook by Evans and Berman (1990). The 10 pages read by all subjects contained approximately equal amounts of regular and boxed material.

We developed a 20 -item multiple-choice test with five alternatives per item. Ten items covered information from regular text, and 10 items covered information from boxed material. Preliminary testing with subjects $(N=27)$ who had not read the selected material yielded no score above $20 \%$ correct on either boxed- or regular-text questions. Moreover, scores on the two types of questions were not significantly different.

\section{Procedure}

When they were recruited, the subjects were assigned a specific day and time for the two experimental sessions. The same group of 3-5 subjects was tested at each session. Before the initial session, each group was randomly assigned to the general or specified condition. Twenty-nine subjects were tested under the general (15 women, 14 men) and specified (16 women, 13 men) conditions.

When the subjects arrived for the first experimental session, they completed an informed consent form and then were given one of the two following sets of verbal instructions. The instructions were repeated twice. The subjects in the general condition were instructed to "carefully read all of the material in the section that has been marked in the textbook on your desk. You will have $30 \mathrm{~min}$ to complete this material. Be prepared to take a test over this material at the session that is scheduled for tomorrow." Instructions for subjects in the specified condition were the same, except that the phrase including the boxes was inserted after the phrase "carefully read all of the material." All subjects were required to stay the full $30 \mathrm{~min}$.

Each subject completed the multiple-choice test $24 \mathrm{~h}$ later at the second session. No time limit was imposed for the completion of this test. The same experimenter conducted all sessions.

\section{RESULTS AND DISCUSSION}

Since preliminary analyses comparing the responses of men and women failed to yield reliable differences, these data were pooled within the general and specified conditions for further analysis. Figure 1 presents the mean correct responses to the regular- and boxed-text questions 


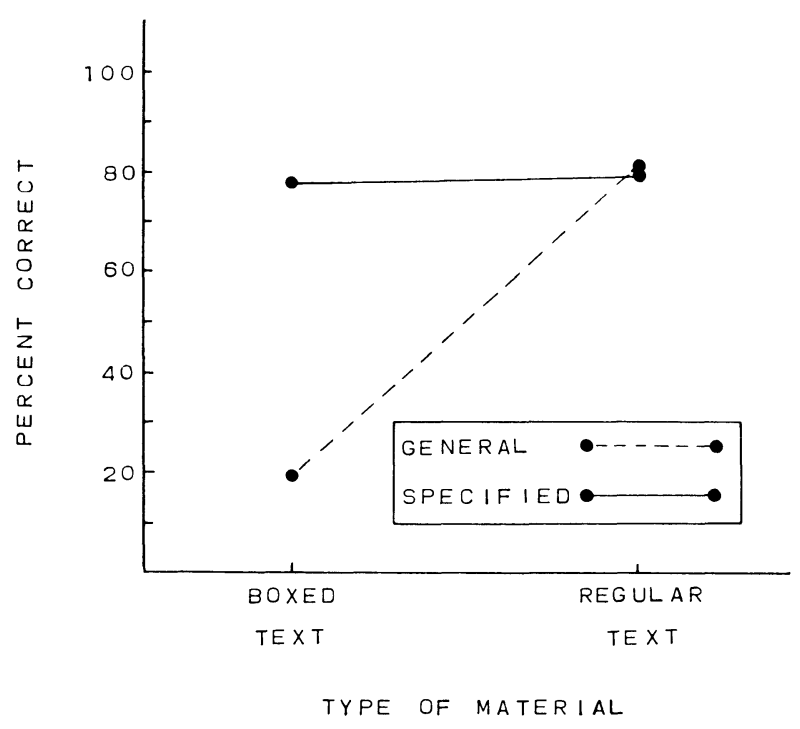

Figure 1. Mean percent correct responses to the regular-text and boxed-text questions for the general and specified groups.

for the general and specified groups. Subjects in the specified group correctly answered almost the same percentage of questions on regular-text material $(81 \%)$ as they did on boxed-text material (79\%). Subjects in the general group correctly answered a comparable percentage of regular-text questions ( $83 \%)$, but only $20 \%$ of boxedtext questions.

An unweighted means analysis of variance incorporating group (general vs. specified) as a between-subject variable and type of question (regular vs. boxed) as a withinsubject variable yielded significant effects of group $[F(1,43)=4.88, p<.05]$ and type of question $[F(1,43)=8.73, p<.01]$, as well as a significant interaction of group $\times$ type of question $[F(1,43)=6.04$, $p<.05]$. The Newman-Keuls procedure, used to probe the significant interaction, indicated that the mean percent of correct answers to the regular-text questions did not differ between the general and specified conditions. However, the percentage of boxed-text questions answered correctly by the specified subjects was significantly higher $(p<.05)$ than the percent correct responses of the general subjects.

The major findings were that subjects in the general and specified conditions correctly answered a comparable number of regular-text questions, but that subjects in the specified condition correctly answered significantly more boxed-text questions. The general condition data are supported by similar results showing a deficit in recall of boxed-text material reported by Miller and Davis (1991, August). These results parallel those of Kumar (1975), who reported that a high percentage of subjects failed to attend to adjunct questions. The implication is that students may not pay as much attention to boxed material as they do to regular text unless they are instructed to do so.

If important material is contained in boxes, instructors must emphasize the need to master this material. Textbook authors and publishers should pay serious attention to this message.

\section{REFERENCES}

Bolger, P. C. (1990, April). Do those 'colored' boxes really work? Paper presented at the Great Plains Students' Psychology Convention, St. Joseph, MO.

Evans, J. R., \& Berman, B. (1990). Marketing (4th ed.). New York: Macmillan.

Goldstein, A. G., Bailis, K., \& Chance, J. E. (1983). Do students remember pictures in psychology textbooks? Teaching of Psychology, 10, 23-26.

Kumar, V. K. (1975). The use of adjunct questions as instructional aids. Teaching of Psychology, 2, 179.

Miller, H. R., \& DAVIS, S. F. (1991, August). Assessing the importance of boxed material in texts. Paper presented at the annual meeting of the American Psychological Association, San Francisco.

(Manuscript received July 30, 1992.) 